\title{
Answer to the letter to the editor of Monica del-Rio-Vellosillo et al. entitled "A comparison of spinal anesthesia characteristics following intrathecal bupivacaine or levobupivacaine in lumbar disc surgery" by Sahin AS, Türker G, Bekar A, Bilgin H, Korfalı G (2013). Eur Spine J 9. doi:10.1007/s00586-013-3082-0
}

\author{
Ayça Sultan Şahin
}

Received: 17 December 2013/Revised: 8 January 2014/ Accepted: 8 January 2014/Published online: 15 January 2014

(c) Springer-Verlag Berlin Heidelberg 2014

We thank Dr. M. del-Rio-Vellosillo et al. [1] for addressing our article [2].

We wish to respond to their questions.

In our study, intravascular (iv) solutions and injection rates were the same in both groups. We did not administer special iv pre-loading. Intrathecal injections were carried out for $20 \mathrm{~s}$ without barbotage or aspiration.

The methods used by our group and by del-Rio-Vellosillo et al. were different as it relates to the dose of local anesthetic and patient position. The most important methodological difference affecting the level of anesthesia and the block duration times between the two studies is the dose of local anesthetic. In our study, $15 \mathrm{mg}$ of bupivacaine or levobupivacaine was administered and, in their study, $12.5 \mathrm{mg}$ was administered.

In our study, spinal anesthesia was administered with the patient in the left lateral decubitus position with a 25-gauge Quincke needle at the L3-L4 interspace. In their study, local anesthetics were administered intrathecally with a 29-gauge Quincke needle at the L3-L4 interspace while the patient was in a seated position.

It is important to note that the patient population was different in the two studies. Del-Rio-Vellosillo et al. studied young patients who underwent arthroscopic knee operations, while our study included patients suffering from back and leg pain with lumbar disc herniation. Due to the differences in the patient groups, patient positions, doses of local anesthetic, and spinal needle size, it is not appropriate to compare the results of the two studies. Instead, the results should be evaluated separately. We believe that the dose of local anesthetic and the position of the patient are the two major factors in understanding why there are differences in the results of the two studies [3].

Conflict of interest None.

\section{References}

1. Del-Rio-Vellosillo M, Garcia-Medina JJ, Pinazo-Duran MD, Abengochea-Cotaina A, Barbera-Alacreu M (2013) Spinal anesthesia for knee arthroscopy using isobaric bupivacaine and levobupivacaine. Anesthestic and neuro-opthalmological assessment. Biomed Res Int. Available at http://www.hindawi.com/ journals/bmri/aip/349034 (in press)

2. Sahin AS, Turker G, Bekar A, Bilgin H, Korfalı G (2013) A comparison of spinal anesthesia characteristics following intrathecal bupivacaine or levobupivacaine in lumbar disc surgery. Eur Spine J 9. doi:10.1007/s00586-013-3082-0

3. Sheskey MC, Rocco AG, Bizzarri-Schmid M, Francis DM, Edstrom H, Covino BG (1983) A dose-response study of bupivacaine for spinal anesthesia. Anesth Analg 62(10):931-935

\footnotetext{
A. S. Şahin ( $\square)$

Department of Anesthesiology and Reanimation, Faculty of Medicine, Uludag University, Bursa, Turkey e-mail: aycasultan@gmail.com
} 